\title{
From Exclusion to Inclusion-a Stepwise Process: a Qualitative Study of How the Reintegration Process Is Experienced by Young People Previously Living on Streets in the Kagera Region, Tanzania
}

\author{
Jeanette Olsson $^{1} \cdot$ Staffan Höjer $^{1}$ - Maria Emmelin ${ }^{2}$ \\ Published online: 5 July 2017 \\ (C) The Author(s) 2017. This article is an open access publication
}

\begin{abstract}
The aim is to explore how young people, after having lived on the streets, experience the reintegration process of returning to their local community. Individual interviews were conducted with young males having experience of reintegration after having lived on the streets. The results show a stepwise process initially signified by ambivalence, moving back and forth and encountering setbacks. The process shows how self-reliance is developed and how agency, resilience, individual and collective capital are part of this. Young people who have lived on the street can successfully reintegrate into their local community when given adequate support.
\end{abstract}

Keywords Street children · Reintegration · Agency ·

Resilience $\cdot$ Social support $\cdot$ Social capital

\section{Introduction}

Children living and working on the street are found in both developing and developed countries (Aptekar and Stoecklin 2013), and are known to face vulnerable and difficult situations (Benitez 2011). Organisations in the past usually focused on assisting the children while on the street or by offering them institutional care. Research has also, to a large extent, concentrated on the situation that these children face while on the street, showing not only that they often lack access to basic

Jeanette Olsson

jeanette.olsson@socwork.gu.se; msjeanetteolsson@hotmail.com

1 Department of Social Work, University of Gothenburg, P.O. Box 720, 40530 Gothenburg, Sweden

2 Department of Social Medicine and Global Health, Lund University, Lund, Sweden needs such as food, shelter, education and health care and experience health problems, violence, exploitation and discrimination, but also that they have agency and are able to form social networks with other children on the street (Ray et al. 2011; Evans 2006; Benitez 2007; Kaime-Atterhög 2012; Walakira et al. 2014). During the past decade, policies have however shifted towards assisting them to reintegrate into a community setting (Corcoran and Wakia 2016; James-Wilson 2007; Feeny 2005).

Reviews to assess the effectiveness of interventions for children living on the street all point out a need for further research on interventions and reintegration outcomes (Hossain and Coren 2015; Coren et al. 2013; Wedge 2013; Ager et al. 2012; Berckmans et al. (2012). The sparse research available has mostly focused on the short-term outcomes of reintegration. The results indicate that children can be successfully reintegrated to the educational system (Salokangas 2010), that there is a need to carefully prepare the children and families before reunification, that underlying problems need to be resolved and that individualised solutions and follow-up work are required (Schrader-McMillan and Herrera 2016; Ferguson et al. 2008). Based on these experiences, guidelines for how such community-based reintegration best can be achieved have been developed (Inter-agency working group on children's reintegration 2016). However, to better understand the effects of community-based reintegration efforts, there is a need to focus on the more long-term outcomes and to explore young people's narratives of their experiences of being reintegrated into the community.

Kagera was one of the first AIDS-affected regions in Tanzania that faced a sizeable impact of the epidemic. Many people in productive age became sick or died, leaving children orphaned, often cared for by old people, who themselves needed care (Ksoll 2007). It is estimated that in 2010, one in eight children in the region was an orphan (National Bureau of 
Statistics 2013). Orphan child-headed families also became common in several locations and villages (Evans 2012; Grant and Yeatman 2012). Similar to other countries in Africa, orphans were to a large extent being cared for by members of their extended families (National Bureau of Statistics 2011). However, these traditional safety nets were not able to cater for all the orphaned children. Thus, some left home to live on the streets (Foster 2000). Other major reasons for children to migrate to the streets were poverty, abuse and maltreatment (Embleton et al. 2016; Olsson 2016; Benitez 2011). Bukoba, the regional capital of the Kagera region, experienced an increase of children joining the street a decade ago (Olsson 2004). To improve the situation, a local organisation started a project to assist children and young people working and living on the street. This offered a natural setting for studying the reintegration process from the children's perspective.

The aim of this paper is to explore how young people in Kagera, after having lived on the streets, experienced the reintegration process of returning to their local community.

The term 'street children' usually covers many different groups of children, and can include children more or less connected to the street. The term has been criticised for defining children by their lives on the street and not capturing their agency (Benitez 2007). In this paper, the term 'children living on the street' is used and defined as children that are sleeping outside or in abandoned buildings in the nights. Reintegration is defined as children leaving their life on the street to return to their local community. This can mean moving to family, relatives, a house of their own, boarding school and even foster care.

\section{Theoretical Framework}

Earlier research on children living on street has identified three theoretical perspectives helpful for understanding their experiences: resilience, agency and social capital (Amoah and Edusei 2014; Davies 2008; Nicholas 2011; Mizen and Ofosu-Kusi 2010). These perspectives have also been used to understand other groups of children in adverse situations (Evans 2012; Leff 2008).

\section{Resilience}

Resilience refers to a situation where individuals have relatively good outcome despite adverse life events and implies relative resistance to overcoming stress and adversity (Rutter 2007). Similarly, children may be doing better than expected, given their history of adverse experiences. Some might be resilient to negative events, but not all. Rutter (2007) argues that there are three considerations to be made; firstly, overcoming adversity depends on the experiences that they have after the adverse event, secondly, resilience cannot be reduced to individual psychological traits, and thirdly, the mediating mechanisms giving rise to resilience might be personal agency or coping strategies, i.e. what individuals do to deal with challenges that they face. Factors promoting resilience can be grouped into assets and resources. Assets refer to individual internal psychological and biological factors, competencies, coping skills and self-efficacy. Resources are factors that are external to individuals and reflected in the nature and quality of relationships, including parental and family support and community organisations (Fergus and Zimmerman 2005).

Studies have shown that children and young people living on the street show considerable resilience in terms of meeting their survival needs, developing social networks and living independently with their peers on the street (Amoah and Edusei (2014). This has led to a shift in thinking about childhood from emphasising their vulnerability to stressing their strengths and considering the connections between risk and resilience factors associated with street life (McAdam-Crisp et al. 2005).

\section{Agency}

Over three decades ago, James and Prout (1997) introduced the concept of children having their own agency, showing that their competencies can influence their social world and that they can take active part in it. This brought about a major shift in childhood research moving away from considering children as passive subjects. The term agency refers to the ability of individuals to act independently and to make their own decisions and choices. Several studies on orphans and vulnerable children and those living on the street have shown that they have a high degree of agency, often linked to resilience (Amoah and Edusei 2014).

A conceptual shift towards realising that children and young people are subjects who speak in their own right and have their own agency to form and influence their life course has also been reflected on in one of United Nations reports, concluding that 'children living and/or working in the streets cannot be considered as a social problem but, instead, as human beings with full potential to contribute to society and as positive agents for change' (United Nations, 2011).

To recognise children's agency does not mean that adults close to the child and society can abdicate from their responsibility to provide the support needed. Children are still less capable of taking care of all aspects of their lives compared to adults. Instead, it means that children should be participating in the decision-making process regarding their lives (Sanders and Mace 2006). Among children living on the street, some will be weaker than others and therefore in need of additional care and support. A critique against the agency concept is also that it has not transformed into real political change for children on the street. Children are to a large degree still denied 
political influence, and their decision-making power is low (Bordonaro 2012).

\section{Social Capital}

Social capital can be seen both as a collective feature that characterises communities with regard to high or low levels of social participation, trust and reciprocity norms (Putnam 2000) and as a resource available to individuals through their involvement in different social networks (Portes 1998). While Putnam focuses largely on the beneficial effects of social capital, other researchers recognise the potential negative aspects; Eriksson (2010) and Portes (2014) observed communities with high social capital risk excluding members that do not fit the norms. Social capital can be divided into structural social capital, which focuses on what people 'do', and cognitive social capital, which focuses on what people 'feel'. Structural social capital refers to participation in networks and can be further divided into bonding (networking within social groups with people similar to one-self, e.g. family and friends), bridging (networking with people that are not alike in terms of social identity) and linking (networking with people with different power and authority) (Szreter and Woolcock 2004).

The concept of social capital has been used in various research areas, e.g. health promotion, public health and HIV prevention, and a link between social capital and self-rated health has been established (Story 2013; Eriksson 2010). Research has shown that there are stronger associations between individual social capital than with collective social capital and positive health outcomes. Regarding individual social capital, the cognitive component has been found to be more important than the structural one (Story 2013). In Tanzania, studies have shown that individual social capital is important for orphans' and vulnerable children's ability to claim their land, resilience and empowerment (Evans 2011, 2012). In studies from Kagera region, the positive role of collective social capital for HIV prevention has also been established, especially through the social groups that were formed facilitating transfer of norms and knowledge important for HIV prevention (Frumence et al. 2014; Frumence 2011).

Having access to social capital has been shown to be important for having a more favourable situation on the street (Amoah and Jørgensen 2014; Nicholas 2011; Stephenson 2001; Ferguson 2004), and weakened social capital has been one reason for children to migrate to the streets (Volpi 2003). Even if there is limited research on the role of social capital in the reintegration of children previously living on street, there are studies indicating that access to social capital facilitates a positive outcome of the reintegration process for former child soldiers (Leff 2008).

In this paper, we used these theoretical perspectives of resilience, agency and social capital as sensitising concepts. This implies that they were used to guide both data collection and the analysis, not steering us in what to see but suggest directions to look (Blumer 1954).

\section{Methods}

\section{Study Setting}

Kagera region is situated in northwestern Tanzania, with a population of 2.5 million. The region consists of eight districts (National Bureau of Statistics 2013). In 2003, a project, referred to as Tumaini, started with an aim to assist the increasing number of children living in the streets and working as domestic workers in Bukoba town. The project was implemented by the Evangelical-Lutheran Church of Tanzania, North-Western Diocese (ELCT NWD) and has, since the beginning, assisted over 750 children. The majority of these children were boys, which is similar to the pattern found in most parts of the world (Aptekar and Stoecklin 2013). The project framework is similar to the recommended pillars of reintegration work set forward in published guidelines by the Inter-agency working group on children's reintegration (2016). The project has records of basic information about individuals who have received support from the project and provided the sampling frame for this study.

\section{Overall Research Design}

This study is part of a larger research project aiming to understand what facilitates young people that have previously lived on street to reintegrate to their local community. The project made use of a mixed-method approach using both qualitative and quantitative methodology with focus group discussions, in-depth interviews and a cross-sectional survey as the main data collection methods. Data from focus group discussions (FGDs) and a cross-sectional survey have been analysed and reported elsewhere (Olsson et al. 2016; Olsson 2016; Olsson et al., forthcoming). These studies focused on reasons to leave home, the children's and young people's situation on the street and as domestic workers as well as their situation after reintegration with regard to sociodemographic factors, occurrence of violence, quality of life and self-rated health. In the current study, we used a qualitative approach to capture the young people's experiences of reintegrating to the community after having lived on the street. Since we wanted to stay close to the informants' lived experiences, individual in-depth interviews were chosen for data collection (Dahlgren et al. 2007; Graneheim and Lundman 2004).

\section{Sampling of Informants}

The informants were sampled among the participants from the cross-sectional survey described earlier (Olsson et al. 2016) 
that had indicated willingness to participate in an individual interview to tell more about their experiences. We aimed at reaching males and females who were between 18 and 24 years that had earlier lived on the streets. According to our judgement, they would be better capable of reflecting back on their previous experiences and able to relate to their current situation than their younger peers. The list of participants in the survey was revisited, and among those that had volunteered for an interview, efforts were made to select informants who came from different districts: urban, semi-urban and rural. We also aimed at interviewing young people that had been reintegrated during varying lengths of time (minimum one year) and had indicated both low and high qualities of life after reintegration. The field coordinator of the survey contacted potential informants, informed them about the aim of the study and asked about their willingness to take part. In the cross-sectional survey, only $6 \%$ of those having lived on the street were girls, but when approached, they did not fit the selection criteria or were not available for an interview. Thus, our study is limited to the experiences of young males.

\section{Data Collection}

The interviews were performed during spring 2015 by the main author (JO) together with the Kiswahili speaking field coordinator who also acted as an interpreter. The interviewer (JO) was not from the region, and did not speak the local language, but had been involved in social work related to young people living on the streets in Bukoba for a period of more than two decades. For the informants to feel confident during the interviews, it was important that the interpreter was from the region, spoke both the local language Kihaya and Kiswahili and had a long experience in interviewing individuals regarding sensitive issues for research purposes. The informants came from three districts: Bukoba municipal, Muleba and Missenye. Rooms were rented in each one of these localities where the informants could be interviewed in a place where privacy could be warranted. The interviews were conducted in Kiswahili/Kihaya since it was important for the informants to feel that they could express themselves freely and use their own words in doing so. Prior to the interviews, the informants were reminded of the purpose and voluntary nature of the study, that confidentiality would be ensured and that they could at any point quit the interview without any impact for them. The interviews were digitally recorded, and lasted between 40 and $120 \mathrm{~min}$, with an average of $1 \mathrm{~h}$.

An interview guide was constructed, based on experiences from the FGDs and the cross-sectional survey described above (Olsson et al. 2016). To develop a rich understanding of the reintegration process, the interview guide covered various themes: the process of leaving the street and starting to reintegrate, current situation with regard to housing and work, social interaction, available network and future plans. The interview guide only served as a guide, and probing questions were used to explore the informants' own views and experiences. After having interviewed 11 young males, a wide range and variation in experience had been captured and no new aspects came up.

\section{Analysis}

To prepare for analysis, the recorded interviews were transcribed verbatim. All that was said either in English, Kiswahili or Kihaya was transcribed. Later the Kiswahili and Kihaya transcripts were translated to English by local interpreters, making it possible for the authors to check that meaning was not lost in translation.

The analysis process followed qualitative content analysis as described by Graneheim and Lundman (2004). This implied that the analysis started with reading each interview in detail followed by identifying and coding meaning unit. The meaning units were not condensed since the interviews were fairly short and concise. The second step included clustering and abstracting codes to categories and sub-categories on a manifest level, still keeping close to what the informants expressed. Later an overall theme was constructed to illustrate the more latent meaning of the text. Using the Excel program facilitated the sorting and clustering of codes.

All three authors coded independently the sections in each interview that was related to leaving the street and the early reintegration process. The coding was afterwards compared and discussed to get a common view of the text. The coding was then completed by the main author and discussed with the co-authors. The theme, categories and sub-categories were developed jointly. After the analytical structure was developed, it was discussed with the interpreter. In a last step, quotes could be identified to illustrate how the interpretations were justified in the data. The analytical process moving from meaning unit to sub-category is illustrated in Fig. 1.

\section{Ethical Approval and Considerations}

Ethical approval was obtained from the Muhimbili University of Health and Allied Sciences (MUHAS) in Dar es Salaam, and appropriate approval from the local authorities was obtained prior to the start of the study. Written consent from the participants was obtained, after they had received information about the study. The research team was aware of the sensitive nature of the topics brought up in the interviews, which could potentially increase stress among the informants. A referral system was therefore set up, and all informants were informed that they could receive support if needed. During the course of the study, two of the informants expressed a need for counselling and the team helped to reestablish contact with the organisation. 
Fig. 1 The coding process, moving from a meaning unit to sub-category

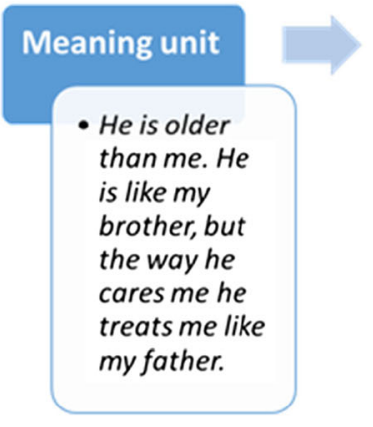

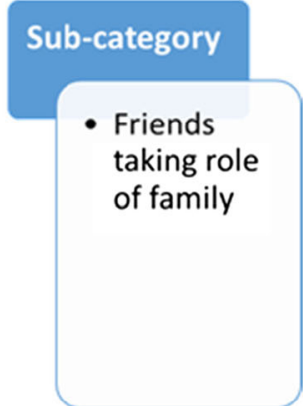

\section{Results}

The analysis was based on interviews with 11 young men, between 19 and 24 years. They all worked, in various sectors. Some stayed alone and others with relatives, friends or wives (see Table 1).

Our analysis resulted in one overall theme, supported by three main categories with sub-categories describing the informants' experiences of their reintegration process (see Fig. 2). The first two categories show a process over time, whereas the third category is ongoing throughout the reintegration process.

The overall theme from social exclusion to inclusion - $a$ stepwise process indicates an overall movement from being identified by others as street children, being looked down upon and discriminated against to being seen mainly as 'normal persons'. However even if they successively felt included and accepted in the community, they constantly struggled to become independent, trying to make sure not to have to face social exclusion again. The first category moving back and forth relates to exit processes that were filled with ambivalence. The exit processes often lasted over a period of time, and included several movements between the street and the organisation before starting a stepwise journey towards a reintegrated life in the community. The next category encountering setbacks captures the new set of challenging problems that the former street children met when starting to reintegrate.
If faced with unrealistic demands, this could mean that they hid problems in fear of being seen to fail and again face exclusion. The last category building self-reliance illustrates a process within them, slowly changing their self-perception and identity, from a 'street child' to feeling being a member in society and living an independent life.

The following section gives a detailed account of the results. It is presented under the headings of the categories and sub-categories and with quotes to illustrate how the interpretation is justified in the data.

\section{Moving Back and Forth}

The main trajectory for the informants can be described as a long process of going back and forth between street and other places such as the organisation, home and boarding school, before settling in the local community. However what actually happened was to a large extent dependent on meeting grownups that had their best interest at heart.

\section{Being Lost But Waiting to be Found}

When the informants talked about what made them leave, the difficult situation on the street they often described that it was not their own initiative; instead, they met some adult who
Table 1 Sociodemographic characteristics of the informants

\begin{tabular}{|c|c|c|c|c|}
\hline No. & Age & District & Housing & Occupation \\
\hline 1 & 24 & Muleba & Alone in rented room & Bicycle taxi driver \\
\hline 2 & 24 & Bukoba rural & $\begin{array}{l}\text { Alone in small house he borrows } \\
\text { from a woman }\end{array}$ & Trainee to be motor bike mechanic \\
\hline 3 & 24 & Bukoba urban & Sharing room with a friend & Casual labour, day labourer \\
\hline 4 & 24 & Missenye & With wife in house he built & Has his own carpenter workshop \\
\hline 5 & 19 & Muleba & Live with brother in a house & Fisherman \\
\hline 6 & 23 & Muleba & With wife in a house & Farmer \\
\hline 7 & 20 & Missenye & Alone in rented room & Factory worker, sugar industry \\
\hline 8 & 23 & Bukoba urban & Alone in rented room & Factory worker, fish industry \\
\hline 9 & 22 & Bukoba urban & Living in house with younger siblings & Motorbike taxi driver \\
\hline 10 & 22 & Bukoba urban & Alone in rented room & Motorbike taxi driver \\
\hline 11 & 19 & Bukoba rural & Alone in a house & Farmer and builder \\
\hline
\end{tabular}


Fig. 2 A summary of the results with theme, categories and subcategories
From exclusion to inclusion - a stepwise process

\begin{tabular}{l} 
Moving back \\
and forth \\
- Being lost waiting to \\
be found \\
- Taking own decsions \\
- Depending on \\
goodwill of trusted \\
grown-ups \\
- Being given second \\
chances \\
\hline
\end{tabular}

Building self reliance

- Keeping contact with family

- Relying on new and old networks

- Being determined not to give up

- Taking pride in stepwise successes

- Giving back offered them assistance. That could be staff from the local organisations or other adults in the city.

I was...about nine years, ...there was one gentleman who was passing by the streets, he took me, we went there at Tumaini. (Int. 5)

Other children described how they met staff from the organisation that they felt that they could trust and therefore dared to go with them to see what they could offer. Often, it started with sitting in a coffee shop in the city to discuss, and after having met a couple of times, they trusted them enough to go with them to the organisation to see what they could offer. Being able to trust the adults that they met was important for them.

\section{Taking Own Decisions}

Those who did take a decision on their own described that they had heard of the organisation and went there to ask for assistance. The tendency was to go there in a small group of two or three boys, which was probably a way to feel safe. It was common for them to gradually shift from the street to the organisation, by continuing to sleep on the street in the beginning and be at the organisation during daytime. But there were also those that moved directly to the organisation's transition home.

Even though they often sought assistance jointly, the reintegration was later individual, with each child taking its own path. Since the children were used to live independently, they often had clear opinions of whom they wanted to move to and what type of education they wanted to have. When the first plan did not work out, they could return to the street for a while before finding something better as indicated by the following quote.

I began looking for a job, fortunately I happened to get a job at Triple " $H$ " restaurant. I stayed there working for a period of three months but the work was tiresome and its payment was 15,000 only. So I decided to leave that job, I later met a man who was building a house and I joined him as a porter. (Int. 10)

\section{Depending on Goodwill of Trusted Grown-Ups}

The narratives illustrated how the informants also after having left the street often had to depend on the good will of trusted grown-ups. Even though they had lived independently for a long time, they were again in a child's position and had to rely on grown-ups. When this worked well, they were listened to and taken seriously as indicated in the quote below:

\section{After we got used to (the center), after two weeks, they asked us 'do you like school', we said yes...so we went there, they took good care of us, and every day after school they checked on our exercise books. (Int. 7)}

They also described instances when grown-ups decided on their behalf, without considering their situation in full or putting other's interest first. The quote below relates to an informant that had been placed in foster care in his friend's family, but when the foster father could not afford school fees, he had to return to the centre, to find an alternative plan.

\section{My friend's father failed to support me since he had two children joining secondary school and I was the third one, so he said that I should be shifted to the centre, and after sometime my transfer forms were processed and I was taken to join Secondary School. (Int. 10)}

\section{Being Given Second Chances}

Since the informants were used to leave non-conducive environments, they continued to use that strategy and were prone 
to change what they wanted to do and where they wanted to stay. Sometimes going back home did not work out, and then, they either went back to the street or the organisation to ask for assistance. Then a new plan would be developed, which could, for example, be vocational school. That might also not work out because they realised that they did not like the subject so they changed the course. The quote below illustrates how one of the informants was given several chances to finally be able to start reestablish himself in the community.

I came back to the street, but she (a staff at the center) found me and asked me why I have come back to street. I told her, she understood me and said she will arrange for me to get a school here... From MEMKWA I was taken to Kashasha Vocational Training centre where I took carpentry studies. But because I did not like carpentry but rather mechanics, I stopped studies after one year and four months. I came back and told her, she agreed and promised to help me. (Int. 2)

\section{Encountering Setbacks}

The reintegration process did not seem to follow a straight line. The interviews included not only several stories about setbacks when starting the reintegration process in, for example, entering the school system or making ends meet but also attempts to find new solutions to overcome them.

\section{Reentering the School System}

The importance of going to school was evident in the interviews. Many of the informants had not been to school for several years, and some had never gone to school at all. Not being given the possibility to attend school had also been one of the important reasons to leave home. In addition, the organisation saw school as a vehicle for change, and assisted them in starting either primary school or MEMKWA. ${ }^{1}$ At the time for reintegration, a school transfer was initiated, so the child could start in a local school, at a level appropriate for their knowledge. Sometimes this worked well; others encountered setbacks. Some parents thought that they were too old to go to school and demanded them to start working. There were also schools that were reluctant to take in someone that was many years older than the classmates. Boarding schools, both vocational and secondary schools, became a solution. Other problems are related to poverty where the parents or caretakers that they were staying with could not afford the required materials

\footnotetext{
${ }^{1}$ MEMKWA is a special education program to provide education opportunities for those who could not be mainstreamed to formal schools. Children aged 10 and above that have missed big portion of school should join MEMKWA for 1-2 years, and after passing the exam for standard four, they can start standard five in ordinary primary school.
}

needed for attending school, e.g. shoes and exercise books. The quote gives an illustration of how the transfer back home resulted in being forced to quit school and start to work.

\begin{abstract}
So I joined primary school standard five, in standard six they told me that 'you will be transferred back home'. Therefore, they processed my transfer. Upon reaching there my father refused, saying 'no...go to your place, build a house and start your own life, for all that period what were you studying, you should have been done by now'. (Int. 11)
\end{abstract}

\section{Facing Difficulties to Make Ends Meet}

The main difficulties for the informants, when starting to reintegrate, had been to find a job after finishing school, especially one where they could earn enough to support themselves. They had various kinds of works and earnings. In the villages, they usually farmed or were fisherman. In the cities, they were factory workers and motorbike taxi drivers; others ran small business or were day labourer. All these different jobs had their own set of challenges. The motorbike taxi drivers usually worked 7 days a week, had to earn enough to first pay the owner of the bikes and the fuel. In addition, they were often stopped by the police and had to pay fines, and feared accidents. The quote below illustrates the risk that they faced of actually having nothing left at all.

The biggest problem is...you might find yourself only making 10000 shilling and if you deduct the boss' 7000 shilling and deduct 3000 for fuel you remain with nothing and so you are forced to sleep hungry. (Int. 10)

The factory workers often had hard work and low pay. The fisherman had a seasonal job where in periods, they did not catch any fish to eat and sell. The day labourer had been rounded up with police and taken to court because it was not legal to be loitering. He was later freed, but this illustrates how vulnerable young people without formal employment are.

\section{Meeting Unrealistic Demands}

When the children left home, it impacted the whole family, and moving back to the family could also mean facing difficulties and unrealistic demands. The parents could have different views of what was important, the same problem that made them leave home the first time might still persist, etc. The young people might be aided in form of school fees and equipment; the siblings might not receive the same support something that could lead to envy. The family members and the young people could also have differing view of what was the best way forward for them. One of the informants 
described how his aunt wanted him to marry before she died. The aunt sold a piece of land to pay the bride price. The boy would have preferred to use money to start a business, but when discussing with the chairperson in the village, the boy agreed with the aunt and complied.

So the chairperson and my aunt looked for a girl and married her for me. (Int. 6)

This 17-year-old informant got married to a 16-year-old girl. He described that they liked each other, but that they were struggling to make ends meet, and some days, they did not have anything to eat. On the other hand, he now had in-laws and was part of a family, instead of being totally alone after the death of the aunt.

For the informants that had been separated from their homes and families for a very long time, it was hard to even remember where they used to live, and the relationships with family members could be very strained. One boy described how the organisation suggested that he should move back to his father, but when he reached, he concluded that the same problems that he earlier had with his father persisted.

\section{I did not spend even a day. We reached there at around eleven am; at twelve I started coming back to town on foot. I reached Bukoba town at two am in the night (Int. 2)}

\section{Hiding Up-Coming Problems}

The informants gave several examples of how they were hiding their problems to others. When they did not have any food, they were reluctant to tell anybody, and rather than asking for it from family members, they went to sleep starving.

I really find it hard to go and tell my brother that I am starving... of course he will give me but personally I don't find it easy to tell him. ...Personally, I feel it's not good to get used to asking for everything from my brother. So I want to avoid such things and also learning to get my own things just the (way) he got his. (Int. 10)

One of the informants recounted a situation when his brother in law, whom he lived with, got very upset because he dared to reveal his difficult situation. The informant had grown out of his shoes, and the family could not afford new ones, and therefore, he had been given a pair of shoes by the school's head master, so he could continue school.

My brother in law said about those shoes... 'who is he to buy you shoes, so he thinks that we cannot afford to take care of you, if so then go and stay at his place'. (Int. 7)

\section{Living in Fear of Failure and Exclusion}

All our informants had a very tough background. They had left home, often at a young age, due to their situation being so difficult that they thought that going to the city on their own might improve their situation. When they ended up on the streets, they faced violence, worse poverty and severe stigma and discrimination. One of the informants described the transition from being seen as an outcast to being treated normally. $\mathrm{He}$, like others, contributed this mainly to appearance, which indicates that this might be a temporary situation that easily could change.

Right now, they take me as a normal person because right now I look like someone who comes from a recognised family. Right now, I am clean, but during that time I was looking dirty and lousy. So, during that time they see us like dirty children. Right now, you cannot tell that I used to live on streets, and that is because right now I have a place of residence, but those days I used to sleep on verandas. I am treated like a person from a different society and not like one from the streets. (Int. 8)

Feelings of happiness and sadness, shame and pride were often related to poverty - if they could get money to buy food and other essential, they felt good; if they had to go to bed hungry, they felt bad. In their vulnerable situation, where job and housing were not always very stable, at least not in the beginning of the reintegration, the risk of failing could mean a dramatic change of situation. The constant worry about the future seemed always present.

What will happen when I reach form four, and you may never know, I might even fail in form four, who will I belong to then? To whom will I go? How will I live? (Int. 7)

\section{Building Self-Reliance}

The informants' stories indicated several ways that their selfreliance was built during the reintegration process. They had varied views about how their lives compared to their peers; one view was that the quality of their lives was equal to others and another view that they had more difficulties compared to their peers. They described that they were poorer and had less support from their families compared to others. At the same time, they described themselves as hard working not giving up their strive for an independent life. I want to live my own life, I don't want to depend on a person. (Int. 5). When asked about dreams for the future, the informants talked about independence and with one of them revealing a strong wish to become 
an equal member of society. I want to be equal like other people. (Int. 11). After having spent years sleeping on the pavement, the dream of a home or their own was also apparent. For me to have my own place, if my guest is looking for me, he finds me at my place. (Int. 3).

\section{Keeping Contact with Family}

An important way of building self-reliance was to keep contact with family members to the extent that it was possible. Often it depended on if they had money for 'airtime' so they could call. It was less often that they could visit the family members. However, the quote below indicates a stronger sense of responsibility for their family members than vice versa.

\section{My dream is to acquire capital and run small entrepre- neurship, for me to move on and have my own place, and make life better for my mom in the village; because she lives like an animal. I can say though she is at her place but still she leads unhappy life, I want both of us to be happy. (Int. 3)}

Even though there were some examples of how they turned to their family members when they faced problems, it seemed that this was not the most common way, but having contact with family was still important.

When I have some money I do go to the village to visit them, sometimes my mother comes to visit me. (Int. 1)

Since many of the informants were orphans, there was much sadness for what they missed, both in closeness and support.

My sadness is when I sit down and wish like if I also had a mother to comfort me. I used to have a father but he also died. (Int. 10)

\section{Relying on New and Old Networks}

The informants described how they, after reintegration, were mainly treated well by community members, and they again attributed this to now looking like other young people. They were no longer dirty, and did not look like they were living on street. The community played an important role for the informants' ability to reintegrate, mentioning significant others such as village leaders, teachers and neighbours that were stepping in and providing assistance.

When I went to the village I was received like their own child. (Int. 10)
They were also invited as members of social groups ${ }^{2}$ in the community. All had friends that were important for them and to a large extent made through work. Having friends allowed them to relax and forget about their problems. Some of the friends and others even took on a parental role. These were people that were closer to them than their biological family, and that supported them emotionally and practically in their daily lives.

He is older than me, he is like my brother but the way he cares me he treats me like my father. (Int. 2)

There were informants who had married and had children while others had a girlfriend. All went to church or mosque either weekly or from time to time. For those that lacked friends and people to turn to, the project played an important role, even after they have turned 18 and finished school. It could be with a request for tools so they could start working as a carpenter or to get help with medical treatment.

\section{Taking Pride in Step-Wise Successes}

The informants talked about being proud when they had succeeded to get a job and managed to support themselves.

I constructed my own house, and he gave me a piece of land. I started to be self-dependent, up to now I depend on myself... I grow tomatoes and sell them to weekly market (Int. 11)

They were also proud over their new role in the society, being seen as community members and feeling that they belonged there.

Right now I can stand before the society and speak something that can easily be understood. The other thing that I am proud of is that right now my life is not bad. It's also not easy to recognize that I have ever lived on streets. Someone might think that I was brought up from a very good family which had no problems. (Int. 8)

\section{Being Determined Not to Give Up}

Even though the informants described how they faced new challenges, they seemed determined not to give up. They really wanted to finish education and those who had started working, worked hard, often 7 days a week. The quote

\footnotetext{
${ }^{2}$ Mainly groups where the members contribute money and can get financial help when they need, for funerals, etc. Only those that have a regular income can participate in those groups, since the contributions have to be made regularly.
} 
illustrates the struggle that one informant faced to be able to finalise his studies.

When exercises books finish, my uncle replenishes. Unfortunately, my uncle was poor, he had a family, so I began going to school and selling sugarcanes. I took them to the gulio (special market day), if I got some money I bought exercise books and continued with studies. (6)

Despite living in an unstable situation, the informants described plans to improve their lives in the future. Their dreams included taking steps to improve their lives and the lives of other family members.

I would want to be a head of the family and have some things to generate income. First and foremost, I show love to my children. (Int. 10)

\section{Giving Back}

It was clear from the informants' stories that they still felt connected to other children living on the street. They remembered how it was to live on the street and felt a great responsibility to help them in one way or another.

\section{I sometimes meet street children sleeping on verandas saying that they have nothing to eat. I cannot just leave because I passed that kind of life, I have tested a street life so I can't just ignore street child. (Int. 1)}

One informant compared his current situation with the situation of the children still living on the street. His wish was to share his experiences of leaving the street and thereby encourage them to find a way to improve their situation.

You can't compare children with homes with street children who are homeless. There is a big difference. You see that boy, we have been together since we were very young, but he is different from me, he does not fight to improve his life, he does not ask himself: Today I am this way, How will I be tomorrow? I am trying my best to bring him here so I can teach him what I already know, for sure I consider street boys my family. (Int. 2)

Another informant illustrated the urge to give back when describing how he allowed children that lived on the street to come to his carpenter shop and work. He found joy in being able to help them become carpenters themselves.

I decided to stay with them because I remember the extent I was supported so I decided to help them as they came... I feel happy when I get money, help the children as much as I can in the small expenditures that they require, that is when I feel happy. (Int. 4)

\section{Discussion}

This study aimed to explore how young people, after having lived on the streets, experienced the reintegration process of returning to their local community. The main finding was that the young people moved from a position of social exclusion to inclusion in this process. However, the process was ambivalent, took time and was marked with setbacks. When they lived on the street, they were severely discriminated and ostracised, but reintegration increased their possibility to feel like members in the community. However during the whole process, they were dependent both on their own agency and others' willingness to support them.

\section{Agency_When Leaving Street}

Leaving the street was an ambivalent process where the young people moved back and forth between the street, the supporting social work organisation and the local community settings. A similar situation has been described in a study of street children in Canada and Guatemala illustrating various dimensions of the process, moving from contemplating leaving the street to redefining one's sense of self (Karabanow 2008). In our study, the success of the reintegration process was related to how the young people were respected and listened to and how their own agency and independence were maintained. But it was also clear that they had to have grownups with capacity and willingness to support them in this transition. Since they were used to leave unfavourable situations, they often continued to leave places for a while or for good. This meant that it was important for them to have people that they could rely on to assist them to come up with alternative plans and solutions if the first one failed. The importance of getting the possibility to build such trustful adult relationships for successful interventions has been pointed out both in a systematic review by Berckmans et al. (2012) and Kaime-Atterhög's thesis (2012) on interventions among street children in Kenya.

The result showed that the path to reintegration was very individual, each one had their own way, and no single model seemed to fit all. The importance of individual tailored solutions for children having lived on the street is something that is also pointed out by Plummer et al. (2007) in their study of children on the street in Khartoum, Sudan. In our study, the grown-ups around the young people sometimes decided on behalf of them, which usually did not work out well. This emphasises the need to respect the young people and their 
abilities, to recognise that many of them had lived independently for a long time, and therefore might be more capable than other young people in the same age to plan for their future. Earlier research from an urban setting in Ghana has also shown that children living on the street have a high degree of agency and resilience that needs to be taken into account when designing programs for them (Amoah and Edusei 2014). In our study, the role of the social support organisation connecting the young people and the community, giving them space and flexibility for transition, respecting their decision and providing assistance for them during the reintegration process was crucial. As discussed by Sanders and Mace (2006), respecting the agency of the children did not mean that the adults abdicated from their responsibility; instead, they continued to provide care and support in various areas of the children's lives: emotionally, practically and financially.

\section{Resilient—But Still Vulnerable When Tackling Challenges}

During the reintegration process, the young people in our study often faced a new set of challenges, not only in terms of reentering the school system and making ends meet, but also in having to deal with strained family relations and conflicts. They started to build up their self-reliance and at the same time changed their view of themselves from 'unclean street children' to an identity more and more as a community member with equal status with others. But they also faced similar problems as other young people in the community since Kagera region is one of the poorest regions in Tanzania, and making ends meet is a challenge for most people (De Weerdt 2010). The disadvantage for the young people in our study was, however, that they lacked care and support from their own families, which others naturally have. This put them in a more vulnerable and exposed situation compared to their peers. This led to an increased need of external support until they had reached a point where they and their families had enough means to sustain their livelihood. Their wish to be independent and showing others that they could handle the societal requirements at times even made them hide their own problems from others and thereby risked not getting basic assistance.

But our results also clearly indicate that the young people in our study had resilience, in terms of individual assets and external resources that helped them cope with the challenges that they faced, without giving up. They worked hard to be self-reliant, to live an independent life with enough earning and to build their own homes. Their capacity of finding friends and other people that they could turn to was also crucial for their ability to reintegrate. Earlier research (Amoah and Edusei 2014; McAdam-Crisp et al. 2005) has also shown that children living on the street resilience and our results suggest that they maintain their resilience also after reintegration.
Our informants' strong urge to give back and help others show how their resilience has made it possible to change their position making it possible to move from being only on the receiving end of support towards being capable of offering help to others. We thus agree with Fergus and Zimmerman (2005) on the importance of focusing interventions for adolescents exposed to risk by assisting them in developing both individual assets and external resources.

\section{Social Capital—for Better and Worse}

The shift from social exclusion to inclusion was possible through the collective social capital in the communities and the young people having developed individual social capital themselves. The young people explained how they found people that took on a parental role for them, how they had friends and sometimes their own family and how they participated in social groups and faith-based activities. This helped them to feel part of the community and no longer seen as a street child. Social capital has also earlier been shown to play a positive role for reintegration outcome, e.g. for sustainable reintegration of former child soldiers in Sierra Leone (Leff 2008). Ferguson (2006) showed in a systematic review that social capital next after poverty is the best predictor of children's well-being. It was also evident in our study how poverty reduced the informants' chances of being able to fulfil their education and decreased their well-being by creating shame. Building social capital is obviously not enough, but should be complemented with efforts to reduce poverty.

Collective social capital mainly seemed to work in favour of the informants. However, it was also clear that the risk of being excluded if not being able to comply with community expectations put stress on the individuals, potentially hampering their development. This dual role of social capital has been pointed out by Portes (2014) and also discussed in previous research on social capital at community level in Sweden and Tanzania. In these case studies, very cohesive communities were shown to be inclusive mainly of those following the norms, but tended to exclude others not behaving in the expected way (Eriksson 2010; Frumence 2011). Thus it would be important to approach the communities to increase their understanding of their important role in the reintegration process.

\section{Methodological Considerations}

The strengths of the study include a prolonged engagement of the first author (JO) in the study setting and the research field as well as a close collaboration with local research assistants and field workers. Still the challenges of working through an interpreter were noted, since the flow of the interviews was hampered by interpretations. To minimise the risk that information was lost, everything said both in English and in local languages was transcribed, and the text in local languages was 
translated into English. The fact that all three authors coded, compared and discussed the sections in each interview that was related to leaving the street and the early reintegration process (peer debriefing) increased the credibility of the interpretations. Discussing the results with a research assistant, well grounded in the study setting, was another way to validate the interpretation of the findings. The results of the reintegration process are limited to young boys, and the transferability of the results to other settings depends on assessment of similarities and the provision of thick descriptions of the research context and procedures (Dahlgren et al. 2004).

\section{Conclusions}

The study reveals that young people who lived on the street can successfully reintegrate in their local community if given support characterised by flexibility and respect. It also demonstrates how discrimination faced while living on the street can decrease. Even when faced with challenges such as poverty, reintegrated children seem capable of becoming equal members of the community.

The results also indicate the important role of organisations and community members in assisting young people during the transition from living on the street to reintegration in the community. As these young people often have weak or no support from their biological families, others need to step in. Our results illustrate not only how the young people find individuals to take on a parental role, but also how dependant they are on contact with a social support organisation. However, the solutions must be individualised and flexible. For successful and sustainable outcomes, it is important to take young people's own agency and resilience into account, while at the same time encouraging the local community to provide the necessary support so that assistance is readily available.

\section{Recommendations for Policy and Practice}

The findings from this study strongly support existing policy recommendations that emphasise the need for the reintegration of children who are or have been living on the street. Social welfare organisations have an important role in this process.

Several policy and practice recommendations emerge from the present study. The first is the importance of building trust as these young people have often been ill-treated by adults. This also means that the support provided should be flexible and built on respect for their own ideas and wishes.

The second recommendation relates to the patience needed to face the setbacks that these young people may meet during the reintegration process. Both social welfare organisations and other adults should be prepared to give second and third chances, be willing to try new solutions and accept that change takes time.
The third recommendation concerns the difficulties that these young people may face making ends meet once they are reintegrated. Provision of temporary social and economic support to them as well as their families from community or social welfare organisations may therefore be crucial.

The fourth recommendation highlights the role of social welfare organisations in providing linkages to key stakeholders, community members and organisations. This can facilitate the young people to build new networks, thereby increasing the social capital needed for their future development.

Finally, being able to give back to others and be a useful member of the community were important for these young people. Both social welfare organisations and the local community should therefore be encouraged to see young people with experience of street life as important resources. Actively involving them as peer educators would be one way of utilising their acquired knowledge and capabilities.

Acknowledgements The authors are very grateful to all the informants who so generously shared their experiences. The authors also thank George Musikula for his coordination and interpretation, Dr. Gideon Kwesigabo for assisting in study design and Muhimbili University of Health and Allied Sciences (MUHAS) in Dar es Salaam for ethical clearance.

This work was partially supported by scholarships to the main author for travel and data collection. Scholarships were given by Kungliga och Hvitfeldtska stiftelsen, Filosofiska fakulteternas gemensamma donationsnämnd and Stiftelsen Lars Hiertas Minne.

\section{Compliance with Ethical Standards}

Ethical Approval All procedures performed in this study involving human participants were in accordance with the ethical standards of the institutional and national research committee and with the 1964 Helsinki Declaration and its later amendments or comparable ethical standards.

Informed Consent Informed consent was obtained from all individual participants included in the study.

Conflict of Interest The authors declare that they have no conflict of interest.

Open Access This article is distributed under the terms of the Creative Commons Attribution 4.0 International License (http:// creativecommons.org/licenses/by/4.0/), which permits unrestricted use, distribution, and reproduction in any medium, provided you give appropriate credit to the original author(s) and the source, provide a link to the Creative Commons license, and indicate if changes were made.

\section{References}

Ager, A., Zimmerman, C., Unlu, K., Rinehart, R., Nyberg, B., Zeanah, C., Hunleth, J., Bastiaens, I., Weldy, A., Bachman, G., Blum, A. B., \& Strottman, K. (2012). What strategies are appropriate for monitoring children outside of family care and evaluating the impact of the programs intended to serve them? Child Abuse \& Neglect, 36, 732-742.

Amoah, P. A., \& Edusei, J. (2014) Demonstrating agency and resilience amidst recurrent health challenges: a case of street children in 
Kumasi Metropolitan Area. Journal of Biology, Agriculture and Healthcare, vol 4, no 12.

Amoah, P. A., \& Jørgensen, S. H. (2014). Social capital, health and health care among street children: a case study of street children in Kumasi metropolitan area, Ghana. Social Capital, 4(4).

Aptekar, L., \& Stoecklin, D. (2013). Street children and homeless youth: a cross-cultural perspective. New York: Springer.

Benitez, S. (2007). State of the world's street children violence. London: Consortium for Street Children (UK).

Benitez, S. (2011). State of the world's street children research. London: The Consortium for Street Children.

Berckmans, I., Velasco, M. L., Tapia, B. P., \& Loots, G. (2012). A systematic review: a quest for effective interventions for children and adolescents in street situation. Children and Youth Services Review, 34(7), 1259-1272. doi:10.1016/j.childyouth.2012.02.014.

Blumer, H. (1954). What is wrong with social theory? American Sociological Review, 18, 3-10.

Bordonaro, L. I. (2012). Agency does not mean freedom. Cape Verdean street children and the politics of children's agency. Children's Geographies, 10(4), 413-426.

Corcoran, S. L., \& Wakia, J. (2016). Using child well-being assessments to track progress in family-based reintegration. Global Social Welfare, 3(2), 137-145. doi:10.1007/s40609-016-0061-5.

Coren, E., Hossain, R., Pardo Pardo, J., Veras, M. M. S., Chakraborty, K., Harris, H., \& Martin, J. (2013). Interventions for promoting reintegration and reducing harmful behaviour and lifestyles in streetconnected children and young people: a systematic review. Campbell Systematic Reviews, 2013, 6.

Dahlgren, L., Emmelin, M., Winkvist, A., \& Lindhgren, M. (2004). Qualitative methodology for international public health. Umeå: Epidemiology and Public Health Sciences, Department of Public Health and Clinical Medicine, Umeå University.

Dahlgren L., Emmelin M., Winkvist A. (2007). Qualitative methodology for international public health. Umeå: Epidemiology and Public Health Sciences, Umeå University.

Davies, M. (2008). A childish culture? Shared understanding, agency and intervention: an anthropological study of street children in northwest Kenya. Childhood, 15(3), 309-330.

De Weerdt, J. (2010). Moving out of poverty in Tanzania: evidence from Kagera. The Journal of Development Studies, 46(2), 331-349. doi: 10.1080/00220380902974393.

Embleton, L., Lee, H., Gunn, J., Ayuku, D., \& Braitstein, P. (2016). Causes of child and youth homelessness in developed and developing countries: a systematic review and meta-analysis. JAMA Pediatrics, 170(5), 435-444. doi:10.1001/jamapediatrics.2016. 0156.

Eriksson, M. (2010). Social capital health and community action-implications for health promotion. Umeå: Umeå University.

Evans, R. (2006). Negotiating social identities: the influence of gender, age and ethnicity on young people's 'street careers' in Tanzania. Children's Geographies, 4(1), 109-128. doi:10.1080/ 14733280600577533.

Evans, R. (2011). 'We are managing our own lives...': life transitions and care in sibling-headed households affected by AIDS in Tanzania and Uganda. Area, 43(4), 384-396. doi:10.1111/j.1475-4762.2010. 00954.x.

Evans, R. (2012). Safeguarding inheritance and enhancing the resilience of orphaned young people living in child- and youth-headed households in Tanzania and Uganda. African Journal of AIDS Research, 11(3), 177-189. doi:10.2989/16085906.2012.734977.

Feeny, T. (2005). In best or vested interests? An exploration of the concept and practice of family reunification for street children. London: The Consortium for Street Children.

Fergus, S., \& Zimmerman, M. A. (2005). Adolescent resilience: a framework for understanding healthy development in the face of risk. Annual Review of Public Health, 26, 399-419.
Ferguson, K. M. (2004). Measuring and indigenizing social capital in relation to children's street work in Mexico: the role of culture in shaping social capital indicators. Journal of Sociology and Social Welfare, 31,81 .

Ferguson, K. M. (2006). Social capital and children's wellbeing: a critical synthesis of the international social capital literature. International Journal of Social Welfare, 15(1), 2-18.

Ferguson, K. M., Dortzbach, K., Dyrness, G. R., Dabir, N., \& SpruijtMetz, D. (2008). Faith-based programs and outcomes for streetliving youth in Los Angeles, Mumbai and Nairobi: a comparative study. International Social Work, 51(2), 159-177. doi:10.1177/ 0020872807085856.

Foster, G. (2000). The capacity of the extended family safety net for orphans in Africa. Psychology, Health \& Medicine, 5, 55-59. doi: 10.1080/135485000106007.

Frumence, G. (2011). The role of social capital in HIV prevention: experiences from the Kagera region of Tanzania [Dissertation]. Umeå: Department of Public Health and Clinical Medicine, Epidemiology and Global Health, University of Umeå.

Frumence, G., Emmelin, M., Eriksson, M., Kwesigabo, G., Killewo, J., \& Moyo, S. (2014). Access to social capital and risk of HIV infection in Bukoba urban district, Kagera region, Tanzania. Archives of Public Health, 72(1), 1.

Graneheim, U. H., \& Lundman, B. (2004). Qualitative content analysis in nursing research: concepts, procedures and measures to achieve trustworthiness. Nurse Education Today, 24, 105-112.

Grant, M. J., \& Yeatman, S. (2012). The relationship between orphanhood and child fostering in Sub-saharan Africa, 1990s-2000s. Population Studies, 66(3), 279-295. doi:10.1080/00324728.2012. 681682.

Hossain, R., \& Coren, E. (2015). Service engagement in interventions for street-connected children and young people: a summary of evidence supplementing a recent Cochrane-Campbell review. Child \& Youth Care Forum, 44(3), 451-470. doi:10.1007/s10566-014-9286-6.

Inter-agency working group on children's reintegration (2016). Guidelines on children's reintegration. http://www. familyforeverychild.org/wp-content/uploads/2016/08/RG_Digital_ DC-1.pdf. Accessed 2016-10-11.

James, A., \& Prout, A. (1997). Constructing and reconstruction childhood (Second ed.). London: Routledge-Falmer.

James-Wilson, D. (2007). Building bridges to mainstream opportunities. Displaced children and orphans funding guidance on funding priorities and parameters. Washington: USAID.

Kaime-Atterhög, W. (2012). From children of the garbage bins to citizens: a reflexive ethnographic study on the care of "street children". Uppsala: Acta Universitatis Upsaliensis.

Karabanow, J. (2008). Creating a culture of hope: lessons from street children in Canada and Guatemala. International Social Work, 46(3), 369-386.

Ksoll, C. (2007). Family networks and orphan caretaking in Tanzania. Department of Economics Discussion Paper Series No 361, University of Oxford, Oxford.

Leff, J. (2008). The nexus between social capital and reintegration of excombatants: a case for Sierra Leone. African Journal on Conflict Resolution, 8(1), 9-38.

McAdam-Crisp, J., Aptekar, L., \& Kironyo, W. (2005). The theory of resilience and its application to street children in the minority and majority world. Handbook for working with children and youth: pathways to resilience across cultures and contexts, 71-88. Sage Publications.

Mizen, P., \& Ofosu-Kusi, Y. (2010). Asking, giving, receiving: friendship as survival strategy among Accra's street children. Childhood, 17(441), 441-454.

National Bureau of Statistics. (2011). Tanzania Demographic and Health Survey, 2010 Final Report (Report No. FR243). Dar es Salaam: NBS \& Calverton, MD: ICF Macro. 
National Bureau of Statistics. (2013). 2012 population and housing census. National Bureau of Statistics, Ministry of Finance: Dar es Salaam.

Nicholas, B. R. (2011). A qualitative investigation of the creation and use of social capital among street children in Bucharest, Romania. Dissertation. The Ohio State University, ProQuest Dissertations Publishing. 3493255.

Olsson, J. (2004). Feasibility study of TUMAINI Children's Center, unpublished.

Olsson, J. (2016). Violence against children who have left home, lived on the street and been domestic workers - a study of reintegrated children in Kagera region, Tanzania. Children and Youth Services Review, 69, 233-240. doi:10.1016/j.childyouth.2016.08.020.

Olsson, J., Höjer, S., Nyström, L., \& Emmelin, M. (2016). Orphanhood and mistreatment drive children to leave home - a study from early AIDS-affected Kagera region, Tanzania. International Social Work. doi:10.1177/0020872816641751.

Plummer, M. L., Kudrati, M., \& Dafalla El Hag Yousif, N. (2007). Beginning street life: factors contributing to children working and living on the streets of Khartoum, Sudan. Children and Youth Services Review, 29(12), 1520-1536. doi:10.1016/j.childyouth. 2007.06.008.

Portes, A. (1998). Social capital: its origins and applications in modern sociology. Annual Reviews Sociology, 24, 1-24.

Portes, A. (2014). Downsides of social capital. Proceedings of the National Academy of Sciences, 111(52), 18407-18408.

Putnam, R. D. (2000). Bowling alone: the collapse and revival of American community. New York: Simon \& Schuster.

Ray, P., Daves, C., Nolan, P. (2011). Still on the street - Still short of rights. Analysis of policy andprogrammes related to street involved children. Geneva: Plan and Consortium for Street Children.

Rutter, M. (2007). Resilience, competence, and coping. Child Abuse \& Neglect, 31(3), 205-209. doi:10.1016/j.chiabu.2007.02.001.
Salokangas, R. (2010). The successes and challenges of reintegrating street children through nonformal education in Maputo City, Mozambique. Tampere: University of Tampere.

Sanders, R., \& Mace, S. (2006). Agency policy and the participation of children and young people in the child protection process. Child Abuse Review, 15(2), 89-109.

Schrader-McMillan, A., \& Herrera, E. (2016). Successful family reintegration of street-connected children: application of attachment and trauma theory. Journal of Children's Services, 11(3).

Stephenson, S. (2001). Street children in Moscow: using and creating social capital. The Sociological Review, 49(4), 530-547.

Story, W. T. (2013). Social capital and health in the least developed countries: a critical review of the literature and implications for a future research agenda. Global Public Health, 8(9), 983-999.

Szreter, S., \& Woolcock, M. (2004). Health by association? Social capital, social theory, and the political economy of public health. International Journal of Epidemiology, 33(4), 650-667.

United Nations Human Rights Office of the High Commissioner. (2011). Protection and promotion of the rights of children working and/or living on the street. Geneva: United Nations Human Rights Office of the High Commissioner.

Volpi, E. (2003). Street children: promising practices and approaches. Washington: World Bank Institute.

Walakira, E.J, Ddumba-Nyanzi, I., Lishan, S., Baizerman, M. (2014). No place is safe: violence against and among children and youth in street situations in Uganda. Vulnerable Children and Youth Studies: An International Interdisciplinary Journal for Research, Policy and Care, 9(4), 332-340.

Wedge, J. (2013). Reaching for home: global learning on family reintegration in low and lower-middle income countries. Interagency Group on Reintegration. http://www.cpcnetwork.org/resource/ reaching-forhome-global-learning-on-family-integration-in-lowand-lower-middle-income-countries/. Accessed 30 January 2014. 